\title{
PENGALAMAN KELUARGA DALAM MERAWAT DEKUBITUS
}

\author{
FAMILY'S EXPERIENCE IN TAKING CARE DECUBITUS ULCER
}

\author{
Rita Sari \\ STIKes Muhammadiyah Pringsewu
}

\begin{abstract}
ABSTRAK
Imobilisasi merupakan masalah yang dihadapi oleh pasien-pasien dengan penyakit kronis, pasien yang sangat lemah dan pasien yang lumpuh dalam waktu lama. Tujuan penelitian ini adalah untuk memperoleh pemahaman yang mendalam tentang pengalaman keluarga dalam merawat anggota keluarga yang mengalami imobilisasi dengan dekubitus di Rumah. Penelitian ini menggunakan metode kualitatif. Partisipan adalah keluarga yang merawat pasien saat di rumah yang mengalami imobilisasi dengan dekubitus. Pengumpulan data dengan wawancara mendalam dengan instrumen utama yaitu diri peneliti sendiri, pertanyaan=pertanyaan tertulis sebagai pedoman wawancara, menggunakan alat perekam dan menggunakan catatan lapangan (field note). Pengambilan sampel menggunakan teknik criterion sampling dengan mengambil 6 partisipan. Analisa data menggunakan pendekatan fenomenologi. Hasil penelitian menunjukkan keluarga mempunyai pengalaman yang positif; bisa lebih sabar, dan menganggap bahwa merawat anggota keluarga yang sakit mempunyai tantangan tersendiri, bisa bersama-sama dengan keluarganya yang lain dalam merawat pasien, bisa memberikan kasih sayang dan kewajiban sebagai anak terhadap orangtua bisa membantu merawatnya. Selain itu juga terdapat pengalaman tidak menyenangkan (negatif) keluarga selama merawat anggota keluarga yang sakit yaitu keluarga merasa lelah, tidak kuat dan bosan selama merawat pasien. Kesimpulan penelitian adalah keluarga mempunyai pengalaman positif dan negatif dalam merawat anggota keluarga dengan decubitus
\end{abstract}

Kata kunci ～: Pengalaman Keluarga, Imobilisasi, Dekubitus

\begin{abstract}
Immobilization is a problem faced by patients with chronic illness, the patients is very weak and paralyzed patients in a long time. This study have purpose to gain a deep understanding of the experience of families in caring for family members is immobilized with pressure sores at home. This study used qualitative methods. Participants are families who care for patients at home who are immobilized with pressure sores. Collecting data with in-depth interviews by means of instrument is the researcher's own self, written questions as an interview, used recording devices and used field notes. Criterion sampling by taking 6 participants. Analysis of data used a phenomenological approach. The results showed that the family had a positive experience; Can be more patient, and assume that caring for a sick family member has its own challenges, being able to be with other families in caring for patients, being able to give affection and obligation as a child to parents can help take care of it. There was also an unpleasant (negative) family experience during the care of sick family members, the family felt tired, not strong and bored during patient care. The conclusion of the study is that families have positive and negative experiences in caring for family members with decubitus
\end{abstract}

Keywords: Family Experience, Immobilization, Pressure sore 


\section{LATAR BELAKANG}

Dekubitus/ luka tekan merupakan masalah yang dihadapi oleh pasien - pasien dengan penyakit kronis, pasien yang sangat lemah dan pasien yang lumpuh dalam waktu lama, bahkan saat ini merupakaan suatu penderitaan sekunder yang banyak dialami oleh pasien - pasien yang dirawat di rumah sakit saat sedang mendapatkan asuhan keperawatan ${ }^{1}$.

Munurut Nurarif dkk dicubitus adalah kerusakan/kematian kulit sampai jaringan dibawah kulit, bahkan menembus otot sampai mengenai tulang akibat adanya penekanan pada suatu area secara terus menerus sehingga mengakibatkan gangguan sirkulasi darah setempat ${ }^{2}$.

Beberapa angka kejadian dekubitus/ luka tekan telah dilaporkan diberbagai Negara, Kejadian luka tekan di Amerika, Kanada dan Inggris sebesar 5-32 \%3. Biaya yang dikeluarkan oleh negara Amerika untuk perawatan luka tekan di rumah sakit meningkat $50 \%$ dari anggaran sebelumnya ${ }^{4}$.

Berbeda dengan Negara Indonesia menurut Suriadi dkk kejadian luka tekan di Indonesia sangatlah tinggi apabila dibandingkan dengan negara-negara lain ${ }^{5}$. secara keseluruhan kejadian luka tekan di rumah sakit mencapai $33 \%{ }^{4}$.

Berbagai penelitian tentang kejadian luka tekan salah satunya ditunjukan oleh penelitian yang dilakukan oleh Chasanah $\mathrm{N}$ tentang gambaran pengetahuan dan sikap keluarga tentang pencegahan dekubitus pada pasien stroke di rumah paska perawatan di RSUD Al-Ihsan Bandung. Hasil penelitian menunjukkan sebagian responden $(55,4 \%)$ berpengetahuan cukup dalam pengetahuan penyebab dan pencegahan dekubitus. Responden yang memiliki sikap positif $(54,1 \%)^{6}$.

Sikap negatif yang ditunjukan oleh keluarga ketika merawat pasien.Penelitian yang dilakukan Rosida E dan Kartika Diah Listyana (2012), tentang pengalaman keluarga dalam merawat Pasien Paska Stroke saat di Rumah di Wilayah Kerja Puskesmas Kedungwuni II. Setelah melakukan wawancara mendalam pada 4 partisipan di Desa Bugangan dan Karangdowo peneliti menemukan permasalahan keluarga dalam merawat pasien paska stroke antara lain stress, rasa lelah, masalah keuangan dan beban keluarga. Keluarga juga memunculkan respon selama merawat antara lain bosan dan marah.

Dari hasil pra survey di rumah sakit Abdul Moeluk (RSAM) Bandar Lampung terdapat masing-masing satu pasien mengalami luka dekubitus yaitu di ruang murai, kutilang, dan bougenville. Hasil wawancara dengan perawat ruang murai dan bougenville bahwa luka dekubitus pada pasien terjadi karena pasien tersebut mengalami penyakit kronis dan hasil wawancara dengan perawat ruang kutilang bahwa luka dekubitus pada pasien disebabkan karena adanya fraktur pada kaki akibat kecelakan, 
sehingga pasien mengalami imobilisasi dengan tirah baring lama selama dirawat di rumah sakit.

Sedangkan hasil pra survey di Rumah Sakit Umum Daerah (RSUD) Pringsewu terdapat 2 pasien dengan luka dekubitus di ruang bedah, hasil wawancara dengan perawat bahwa luka dekubitus yang dialami oleh pasien tersebut sudah ada saat pasien berada di rumah, pasien tersebut mengalami imobilisasi karena penyakit kronis dan dari catatan pasien dengan imobilisasi di rekam medik RSUD Pringsewu peneliti melakukan pra survey langsung ke rumah pasien yang bertempat tinggal tidak jauh dari RSUD Pringsewu yaitu sekitar daerah pringsewu didapatkan 8 pasien pernah dirawat di RSUD Pringsewu yang sudah dilakukan perawatan di rumah oleh keluarga mengalami dekubitus, dari hasil pra survey beberapa rumah sakit dan survey langsung ke rumah pasien bahwa pasien yang mengalami imobilisasi dengan dekubitus lebih banyak dirawat oleh keluarga di rumah.

Penelitian ini bertujuan untuk memperoleh pemahaman yang mendalam tentang pengalaman keluarga dalam merawat anggota keluarga yang mengalami imobilisasi dengan dekubitus di Kabupaten Pringsewu.

\section{METODE}

Penelitian ini merupakan penelitian kualitatif dengan pendekatan fenomenologi. Dalam penelitian kualitatif, studi fenomenologi merupakan pendekatan untuk mengambarkan arti dari pengalaman hidup pada beberapa individu tentang suatu konsep atau fenomena. Oleh karena itu pendekatan ini dipilih karena penelitian ini mencoba untuk menggali arti dan makna pengalaman keluarga dalam merawat pasien imobilisasi dengan ulkus diabetes mellitus.

Teknik pengambilan sampel yang yang digunakan adalah criterion sampling yaitu informan yang memenuhi kriteria tertentu. Sampel dalam penelitian ini adalah keluarga yang merawat anggota keluarga yang mengalami imobilisasi dengan dekubitus, maka dalam penelitian ini data diambil dari 6 partisipan dengan karakteristik sesuai dengan kriteria inklusi yang telah ditetapkan yaitu bersedia menjadi partisipan, memiliki anggota keluarga yang mengalami imobilisasi dengan dekubitus, partisipan merupakan pemberi perawatan utama pada pasien imobilisasi di rumah, serta mampu menceritakan pengalamannya sebagai pemberi perawatan pada anggota keluarga yang mengalami imobilisasi dengan dekubitus. Sedangkan kriteria pasien yang ditetapkan adalah pasien yang mengalami imobilisasi dan sudah terdapat luka dekubitus.

Peneliti melakukan pengolahan data dengan cara mendokumentasikan data hasil wawancara mendalam dan catatan lapangan dari pengalaman pemberi perawatan dalam merawat pasien imobilisasi dengan ulkus diabetik segera setelah proses wawancara selesai. Pendokumentasian hasil 
wawancara dilakukan dengan memutar hasil rekaman.

\section{PEMBAHASAN}

\section{Tema Peran Perawatan Keluarga}

Hasil penelitian menunjukan bahwa semua partisipan yang berperan dalam merawat anggota keluarga yang sakit saat di rumah adalah anggota keluarga yang wanita, yaitu partisipan berperan dalam membantu pemenuhan kebutuhan seharihari pasien.

Hasil penelitian ini sejalan dengan penelitian yang dilakukan oleh Ulya I dkk tentang "Hubungan Pengetahuan dengan Kemampuan Keluarga Merawat Lansia Hipertensi di Kelurahan Karangayu Semarang”, menunjukan bahwa dari 70 responden sebagian besar berjenis kelamin perempuan yaitu sebanyak 40 responden $(57,1 \%)$, sedangkan jenis kelamin laki - laki sebanyak 30 responden $(42,9 \%)^{7}$.

Menurut Mubarak bahwa pemberi perawatan terbesar adalah seorang wanita ${ }^{8}$. Wanita lebih kepada mengerjakan perawatan yang lebih sulit seperti buang air, mandi, berpakaian, sedangkan laki-laki lebih kepada kebutuhan finansial, perencanaan perawatan ${ }^{9}$.

Berdasarkan uraian diatas dapat peneliti simpulkan bahwa dalam penelitian ini yang berperan dalam merawat anggota keluarga yang sakit saat di rumah adalah anggota keluarga yang wanita yang membantu dalam pemenuhan kebutuhan sehari - hari pasien. Hal ini dapat dibuktikan berdasarkan pernyataan partisipan yang menyatakan bahwa partisipan membantu dalam pemenuhan kebutuhan sehari-hari pasien seperti membantu pemenuhan kebutuhan nutrisi (makan, minum), eliminasi (BAK, BAB) dan personal hygiene (mandi).

\section{Tema Mengidentifikasi Masalah Penyebab Dekubitus}

\section{a. Latihan aktifitas/ Mobilisasi pasien}

Hasil penelitian menunjukan bahwa semua partisipan mengungkapkan anggota keluarga yang mengalami imobilisasi dengan waktu yang lama semuanya pernah dan sedang mengalami dekubitus, akan tetapi partisipan sebagai anggota keluarga yang merawat pasien selama di rumah kurang memahami proses terjadinya luka dekubitus tersebut. Partisipan membantu semua dalam kebutuhan pasien, akan tetapi tidak sering dalam membantu melakukan latihan aktifitas/ mobilisasi terhadap pasien.

Orang yang tidak dapat bergerak harus sering diputar dan diresposisi dan seprai mereka harus selalu terpasang kencang. Bagi pasien yang hanya dapat berbaring atau duduk dikursi roda, bagian-bagian tubuh yang paling berisiko antara lain adalah punggung bawah (sakrum), pantat, paha, tumit, siku, bahu dan tulang belikat (skapula). Sekali sehari, gunakan spons kering 
untuk membantali titik tekanan ini agar mencegah tertekannya saraf dan terbentuknya dekubitus ${ }^{10}$.

Berdasarkan uraian diatas dapat peneliti simpulkan bahwa dalam penelitian ini pasien yang mengalami imobilisasi tidak dilakukan latihan aktifitas/ mobilisasi oleh anggota keluarga yang merawat pasien. Hal ini dapat dibuktikan dari pernyataan partisipan yang mengatakan bahwa partisipan hanya membantu dalam pemenuhan kebutuhan sehari-hari pasien, dan kurang memahami bahwa pasien yang hanya tidur terbaring di kamar tidur harus dilakukan latihan aktifitas/mobilisasi secara rutin agar tidak terjadi tekanan yang berkelanjutan sehingga menyebabkan luka dekubitus.

\section{b. Kelembaban kulit pasien}

Hasil penelitian menunjukan bahwa salah satu faktor risiko yang menyebabkan terjadinya luka dekubitus pada pasien juga disebabkan oleh kelembapan kulit pasien yang diakibatkan oleh feses dan urin yang mengakibatkan kulit area pasien menjadi lembab. Akan tetapi keluarga kurang mengetahui informasi bahwa kelembapan yang diakibatkan oleh feses dan urin karena pasien yang selalu menggunakan pempers akan menjadi area kulit pasien lembab dan menjadi salah satu faktor resiko terjadinya luka dekubitus pada pasien.

Berdasarkan hasil kajian dapat peneliti simpulkan bahwa terjadinya dekubitus pada pasien disebabkan karena kelembapan diarea sekitar kulit pasien. Hal ini dapat dibuktikan dari pernyataan partisipan yang menyatakan bahwa buang air besar (BAB) dan buang air kecil (BAK) pasien dilakukan dipempers saja sehingga mengakibatkan area sekitar kulit pasien yang terkena feses dan urin menjadi lembab.

\section{c. Tema Memutuskan Tindakan Kesehatan yang Tepat Bagi Keluarga}

Hasil penelitian menunjukan bahwa

keluarga memutuskan tindakan kesehatan yang tepat bagi keluarga ketika terjadi luka dekubitus pada anggota keluarga yang mengalami imobilisasi.

Selain membuat keputusan tindakan kesehatan yang tepat, keluarga juga memberi perawatan pada anggota keluarga yang sakit. Seringkali keluarga telah mengambil tindakan yang tepat, tetapi jika keluarga masih merasa mengalami keterbatasan, maka anggota keluarga yang mengalami gangguan kesehatan perlu memperoleh tindakan lanjutan atau perawatan agar masalah yang lebih parah tidak terjadi. Perawatan dapat dilakukan di institusi pelayanan kesehatan atau di rumah apabila keluarga telah memiliki kemampuan melakukan tindakan untuk pertolongan pertama ${ }^{8}$.

Berdasarkan uraian diatas dapat peneliti simpulkan bahwa dalam penelitian ini keluarga memutuskan tindakan kesehatan yang tepat bagi keluarga ketika terjadi luka dekubitus pada 
anggota keluarganya yang mengalami imobilisasi, yaitu dengan cara mencari informasi kepada tenaga kesehatan tentang proses terjadinya luka dekubitus dan bagaimana cara merawatnya. Hal ini dapat dibuktikan dari pernyataan partisipan yang mengatakan bahwa keluarga mencari informasi kepada tenaga kesehatan yang ada di lingkungan tempat tinggalnya seperti Mantri, perawat, dan Bidan desa dan melakukan perawatan luka dekubitus secara mandiri.

\section{d. Tema Meningkatkan Mutu Kesehatan Keluarga}

Hasil penelitian menunjukan bahwa keluarga membantu dalam memenuhi kebutuhan sehari-hari pasien yang mengalami imobilisasi guna meningkatkan mutu kesehatan pasien seperti pemenuhan nutrisi, eliminasi dan personal hygiene.

Berdasarkan uraian diatas, dapat peneliti simpulkan bahwa keluarga meningkatkan mutu kesehatan pasien yang mengalami keterbatasan dalam melakukan aktifitas sehari-hari dengan cara membantu dalam pemenuhan kebutuhan seharihari pasien. Hal ini dapat dibuktikan dengan pernyataan semua partisipan yang menyatakan bahwa keluarga yang berperan merawat pasien membantu dalam semua kebutuhan sehari-hari pasien mulai dari pemenuhan nutrisi (makan, minum), eliminasi (BAK, BAB), dan personal hygiene (mandi).

\section{e. Tema Pengalaman Menarik Keluarga Selama Merawat}

Hasil penelitian yang didapatkan oleh peneliti dimana pada keluarga yang berperan selama merawat pasien ditemukan pengalaman yang menurut keluarga bahwa pengalaman tersebut menyenangkan atau pengalaman yang positif bagi keluarganya.

Berdasarkan uraian diatas dapat peneliti simpulkan bahwa keluarga yang berperan merawat anggota keluarga yang mengalami imobilisasi dengan dekubitus mengganggap bahwa pengalamannya dianggap sebagai pengalaman yang positif bagi keluarga, karena keluarga bisa lebih sabar, dan menganggap bahwa merawat anggota keluarga yang sakit mempunyai tantangan tersendiri, bisa bersama-sama dengan keluarganya yang lain dalam merawat pasien, bisa memberikan kasih sayang dan kewajiban sebagai anak terhadap orangtua bisa membantu merawatnya.

\section{KESIMPULAN}

1. Keluarga menganggap bahwa pengalamannya selama merawat anggota keluarga yang mengalami imobilisasi dengan dekubitus sebagai pengalaman yang positif bagi keluarga, karena keluarga bisa lebih sabar, dan menganggap bahwa merawat anggota keluarga yang sakit mempunyai tantangan tersendiri, bisa bersama-sama dengan keluarganya yang lain dalam merawat pasien, bisa memberikan 
kasih sayang dan kewajiban sebagai anak terhadap orangtua bisa membantu merawatnya.

2. Pengalaman tidak menyenangkan (negatif) keluarga selama merawat anggota keluarga yang sakit yaitu pernyataan partisipan yang mengatakan bahwa dirinya merasa lelah, tidak kuat dan bosan selama merawat pasien. Partisipan mengeluhkan ketika membantu dalam pemenuhan sehari-hari pasien, karena dilakukan setiap hari dan sudah terhitung dalam waktu yang cukup lama dan masalah luka dekubitus pada pasien juga dikeluhkan oleh keluarga, karena munculnya luka dekubitus pada pasien akan menambah masalah baru pada pasien dan keluarga yang merawat.

\section{SARAN}

Perlunya peningkatan pelayanan yang lebih baik, terutama dalam hal pendidikan kesehatan dan perencanaan pulang tentang bagaimana perawatan selanjutnya saat di rumah, bukan hanya kepada pasien tetapi juga kepada keluarga yang ikut serta berperan merawat pasien.

\section{DAFTAR PUSTAKA}

1. Morison, Moya J (2013), Manajemen Luka. Jakarta : EGC

2. Nurarif \& kusuma, (2015), Aplikasi asuhan keperawatan berdasarkan Diagnosa Medis dan NANDA, Jogjakarta: Media Action
3. Spilsbury K, Nelson A, Cullum N, Iglesias C, et al. (2007). Pressure ulcers and their treatment and effects on quality of life: hospital inpatient perspectives. Journal of Advanced Nursing 57(5):494-504.

4. Elysabeth D, (2010), Pengaruh posisi miring 30 derajat terhadap kejadian luka tekan grade I (non blanchable erythema) pada pasien stroke di Siloam Hospitals. http://lontar.ui.ac.id/opac/themes/libri2/detail.j sp?id=20282630\&lokasi=lokal

5. Suriadi et al (2007), Attitude of Nurses towards the Use of Braden Scale in Intensive Care Units and Medical Wards

6. Chasanah N, (2013), Gambaran pengetahuan dan sikap keluarga tentang pencegahan dekubitus pada pasien stroke di rumah pasca perawatan di RSUD Al-Ihsan Bandung tahun 2013. perpustakaan.poltekkesbandung.ac.id/

7. Ulya I. dkk, (2013). Hubungan Pengetahuan dengan Kemampuan Keluarga Merawat Lansia Hipertensi di Kelurahan Karangayu Semarang.ejournal/index.php/ilmukeperawatan/article/.../ 147

8. Mubarak, WI, Chayatin, N, Santoso, BA. (2012), Ilmu Keperawatan Komunitas: Konsep dan Aplikasi. Penerbit Salemba Medika, Jakarta

9. Julianti E, (2013), Pengalaman Caregiver dalam Merawat Pasien Pasca Stroke Di Rumah Pada Wilayah Kerja Puskesmas Benda Baru Kota Tangerang Selatan. repository.uinjkt.ac.id/

10. Sinaga J. Dkk (2010). Hubungan Pengetahuan Keluarga dengan Sikap dan Tindakan dalam Meningkatkan Kapasitas Fungsional Pasien Pasca Stroke di Lingkungan III Kelurahan Dwikora Medan 2010. sari-mutiara.ac.id 